\title{
Nick Dubin: Asperger Syndrome and Anxiety-A Guide to Successful Stress Management
}

\author{
Jessica Kingsley Publishers, London, 2009, 222 pp., ISBN 978-1-84310-895-5, \\ $\$ 19.95$ (paper)
}

\author{
Anjali Bhatara
}

Published online: 2 October 2009

(C) The Author(s) 2009. This article is published with open access at Springerlink.com

In this short but informative guide for adults with Asperger syndrome (AS), Nick Dubin draws from sources as varied as cognitive behavioral therapy, mindfulness, Judaism, Jungian psychology, and perhaps most intriguingly, his own experiences as a person with AS. Using these sources combined with his unique perspective, he teaches adults with AS specific strategies for dealing with their daily anxiety. There is a tendency among researchers and clinicians studying autism spectrum disorders to focus on children rather than adults; this is not surprising for a developmental disorder, which can be most easily treated in childhood. However, this imbalance increases the importance of a book like Dubin's, which is aimed at adults with AS and outlines ways that these adults can help themselves.

The first two chapters form a foundation for the rest of the book. In them, Dubin discusses the importance of becoming aware of patterns of thinking and which specific situations are frequently difficult. He begins with a general discussion of what anxiety is, why we experience it, and how humans deal with it, both healthily and unhealthily. Then he narrows the focus to people with AS and the main reason for the book: “...life for a person with Asperger's tends to include more than its fair share of anxiety.... and it is quite easy to take pity on one's self or feel more anxious. But that's not what this book is advocating. The rest of this book will arm you with clear strategies to help you reduce anxiety in all facets of your life" (p. 62).

After the initial discussion of general human responses to stress and anxiety, he offers specific ways of thinking

\footnotetext{
A. Bhatara $(\square)$

62-132 Center for Health Sciences, David Geffen School of Medicine at UCLA, Los Angeles, CA 90095, USA

e-mail: abhatara@mednet.ucla.edu
}

that are shared by many people with AS. Then, he relates these thought patterns to the relatively frequent experiences of anxiety among people with AS. For example, “...you will likely make more social faux pas than most people. The significance you attach to these perceived social mistakes will contribute directly to your level of anxiety" (p. 51).

Starting with the third chapter, Dubin delves into more specific strategies for managing anxiety. He is a proponent of cognitive behavioral therapy (CBT) and devotes the longest chapter in the book to it. His enthusiasm for this therapy is justified; several studies have shown that CBT reduces anxiety in children with high-functioning autism or Asperger syndrome (Ooi et al. 2008; Sofronoff et al. 2005; Wood et al. 2009). Although evidence specific to adults is scarce, the available evidence provides no reason to expect less of an effect for adults undergoing CBT.

For the remainder of the book, Dubin discusses how to apply various strategies (CBT, mindfulness and others) to big aspects of life such as employment, relationships, and spirituality, and how to select a good psychotherapist, keep healthy, and deal with shame and meltdowns. He draws from religion, philosophy, and science often in equal measures, giving the reader many options for fighting anxiety.

Dubin writes in an easy-to-read conversational style, unafraid of using personal examples to illustrate his points. One could imagine that a book so based on personal experience would apply only to a small subset of individuals who have had the exact same set of experiences or a personality similar to the author. However, Dubin is careful to relate his thoughts and experiences to general concepts, and it is likely that his psychological training has given him a broader perspective. With this combination of experience and training, he succeeds at providing the reader with supportive understanding without coddling. At no time 
does Dubin make value judgments about the "rightness" or "wrongness" of ways of thinking, but the reader is strongly encouraged to make life changes and is given several different ways to surmount obstacles, leaving little room for passivity.

Some of Dubin's opinions and strategies may be influenced by the "neurodiversity movement", a group of people who want to bring the focus away from curing or treating autism (and thus reinforcing its status as a disorder) and toward accepting it as simply a different way to live. Though he never says it outright, he hints that he is a supporter of this movement. Dubin refers to aspects of AS such as "unconventional social skills" (p. 21) and "nonconformist behaviors" (p. 43) categorizing them more as ways of being along the spectrum of normal human behaviors rather than as symptoms of a disorder. He encourages his readers with AS to take control of their own lives and understand their own strengths and weaknesses. "Since I consider those who are diagnosed with Asperger's to be the greatest experts (and teachers) in describing the experience of having Asperger's, I believe you and I know more than a lot of the so called "experts"' (p. 43).

This focus on accepting AS as a way of being instead of as a disorder may be helpful for meeting Dubin's goal with this book, which is to give his readers the capacity to help themselves. Readers who think of themselves as "different" instead of "disordered" may find it easier to acknowledge their limits and areas of difficulty while still focusing on using their capabilities and improving their performance in challenging situations. Dubin's book is not idealistic-he is careful to frequently discuss limits and issues widely shared by people with AS and the effects that these can have on the prevalence of anxiety in daily life. Ultimately, his message is one of encouragement and empowerment: "All your life, people have told you what you couldn't do, that you have a lot of shortcomings and disabilities. In this book, I've tried to encourage you to define yourself and not let others limit your vision" (p. 191).

Open Access This article is distributed under the terms of the Creative Commons Attribution Noncommercial License which permits any noncommercial use, distribution, and reproduction in any medium, provided the original author(s) and source are credited.

\section{References}

Ooi, Y. P., Lam, C. M., Sung, M., Tan, W. T. S., Goh, T. J., Fung, D. S. S., et al. (2008). Effects of cognitive-behavioural therapy on anxiety for children with high-functioning autistic spectrum disorders. Singapore Med J, 49(3), 215-220.

Sofronoff, K., Attwood, T., \& Hinton, S. (2005). A randomised controlled trial of a CBT intervention for anxiety in children with Asperger syndrome. J Child Psychol Psychiatry, 46(11), 11521160.

Wood, J. J., Drahota, A., Sze, K., Har, K., Chiu, A., \& Langer, D. A. (2009). Cognitive behavioral therapy for anxiety in children with autism spectrum disorders: a randomized, controlled trial. J Child Psychol Psychiatry, 50(3), 224-234. 